\title{
RELEITURA DE PINTURAS EM TEMPOS DE PANDEMIA: UMA ANÁLISE SEMIÓTICA
}

\author{
REREADING OF PAINTINGS IN PANDEMIC TIMES: A SEMIOTIC ANALYSIS
}

\author{
Recebido: 28/10/2020 Aprovado: 06/12/2020 Publicado: 10/01/2021 \\ DOI: $10.18817 /$ rlj.v4i02.2395
}

\begin{abstract}
Amanda Gabriella Lima Leal ${ }^{1}$
Orcid id: https://orcid.org/0000-0003-1278-0625

Ana Jackelline Pinheiro Porto ${ }^{2}$

Orcid Id: https://orcid.org/0000-0003-1278-0625
\end{abstract}

\begin{abstract}
Resumo: Este artigo tem por objetivo realizar uma análise semiótica de duas releituras de pinturas renomadas ("Mona Lisa", de Leonardo da Vinci e "O Grito", de Edvard Munch), produzidas por alunos do 8 ano do Ensino Fundamental, do colégio Marista da cidade de São Paulo, tendo como temática principal a adaptação da produção artística ao contexto da pandemia mundial por covid19, ocasionada pelo novo coronavírus. A análise teve como aporte teórico e metodológico a tríade de categorias propostas por Charles Sanders Peirce: Primeiridade, Secundidade e Terceiridade. Tais categorias peirceanas nos proporcionam uma melhor análise dos níveis de interpretação e atribuição de sentido pelos quais a mente humana atravessa ao ler as imagens. Em vista disso, para realização de nossas análises, nos apoiamos nas elaborações de Peirce (2005 apud MELO e MELO, 2013), Ilari (2011), Nicolau, M.; Abath; Laranjeira; Moscoso; Marinho V. Nicolau (2010), Santaella (2005), entre outros teóricos. Assim, propomos, através de uma análise interpretativa, adentrar as camadas de interpretação e explorar os sentidos que podem ser atribuídos às imagens produzidas pelos alunos.
\end{abstract}

Palavras-chave: Pinturas. Semiótica peirceana. Pandemia. Mona Lisa. O Grito.

Abstract: This article aims to carry out a semiotic analysis of two reinterpretations of renowned paintings ("Mona Lisa", by Leonardo da Vinci and "The Scream", by Edvard Munch), made by 8th grade elementary school students from the Marist school in São Paulo, having as main theme the adaptation of the artistic production to the context of the covid-19 pandemic, caused by the new coronavirus. The analysis had as theoretical and methodological support the triad of categories proposed by Charles Sanders Peirce: Firstness, Secondness and Thirdness. Such Peircean categories provide us with a better analysis of the levels of interpretation and attribution of meaning that the human mind goes through when reading the images. In view of this, to carry out our analyses, we rely on the elaborations of Peirce (2005 apud MELO \& MELO, 2013), Ilari (2011), Nicolau, M .; Abath; Orange; Moscoso; Marinho V. Nicolau (2010), Santaella (2005), among other theorists. Thus, we propose, through an interpretative analysis, to penetrate the layers of interpretation and explore the meanings that can be attributed to the images produced by the students.

Keywords: Paintings. Peircean semiotics. Pandemic. Mona Lisa. The Scream.

\section{Introdução}

\footnotetext{
1 Mestranda em Linguística na UFPI, professora de Leitura e Produção de Texto na Educação Básica, membro do Núcleo Cataphora - Núcleo de Pesquisa em Texto, Gênero e Discurso. E-mail: amandaglimaleal@gmail.com

2 Mestranda em Letras (Linguística) pelo Programa de Pós-Graduação em Letras da Universidade Federal do Piauí (PPGEL/UFPI). Graduada em Letras- Língua Portuguesa pela Universidade Federal do Piauí (UFPI). É membro do Núcleo de Pesquisa em Texto, Gênero e Discurso (CATAPHORA), na UFPI. E-mail: jackellinepinheiro@ufpi.edu.br
} 
A compreensão do mundo e dos seres, desde os tempos mais primitivos, ocorrem entre si através da linguagem, seja através das pinturas rupestres na PréHistória, até o desenvolvimento dos sistemas iniciais da escrita na Mesopotâmia, que, como aponta Gomes et. al (2019), tinham a função de controlar os produtos agrícolas, manter as informações acerca de negócios, expressar a religião, a arte, dentre tantas outras funções. Por um longo período de tempo, a escrita teve seu valor sobreposto à imagem, uma vez que ela era tida como uma expressão concreta da língua, além de ter uma grande importância na organização da sociedade.

Entretanto, com a evolução social e tecnológica, um novo tempo surgiu para a imagem, em que ela se tornou presente nos mais diversos espaços do cotidiano, seja nas ruas, prédios, outdoors, televisões, computadores, isto é, tornando-se mais acessível e não sendo mais algo restrito aos ambientes artísticos, como museus e templos religiosos, por exemplo. Assim, com a imagem cada vez mais imersa nos meios sociais, muitos estudos despontaram a fim de entender como ela se compõe para alcançar determinado propósito comunicativo.

Tais estudos, porém, mesmo se tornando mais comuns na atualidade, não tiveram início agora, uma vez que alguns estudiosos já compreendiam a imagem também como um signo. Dentre esses estudiosos, destaca-se Charles Sanders Peirce, que foi um cientista das mais diversas áreas do conhecimento e elaborou inúmeras concepções para a área da Semiótica, propondo dez divisões triádicas para a compreensão do significado de todos os signos, que podiam ser verbais ou não (imagéticos, sonoros, entre outros).

Dessa forma, compreendendo a imagem como um signo constituído de sentido, é que propomos, neste artigo, analisar releituras de pinturas clássicas, reconhecidas no mundo inteiro, "Mona Lisa", de Leonardo da Vinci, e "O Grito", de Edvard Munch, realizadas por alunos do ensino fundamental, em meio a pandemia. Tal atividade teve o propósito de representar a situação atual que o mundo tem enfrentado, além de conscientizar as pessoas sobre como se protegerem do novo coronavírus (covid-19). Esta análise ocorreu com base na tricotomia de Peirce, Primeiridade, Secundidade e Terceiridade, a fim de compreender como as imagens se compuseram para construir um sentido final ao interpretante. 
Neste artigo, buscamos trazer as contribuições breves e iniciais sobre a Semiótica, apresentando, em primeiro lugar, os antecedentes da sua instituição enquanto campo do saber, com as concepções de Ferdinand de Saussure (apud ILARI, 2011), para, em seguida, trazer os conceitos desenvolvidos por Charles S. Peirce, que embasam e fundamentam nossa análise. Em seguida, detalhamos na metodologia a fonte das imagens, quais categorias foram analisadas, além de apontar algumas pesquisas prévias que também trabalharam com análise de imagens com base nessa tricotomia. Por fim, apresentaremos a análise semiótica das duas imagens, descrevendo o que foi identificado em cada categoria.

\section{Análise semiótica de imagens: perspectiva de Charles S. Peirce}

Um dos grandes marcos do século $X X$, no panorama dos estudos linguísticos, é a consolidação da Linguística Moderna enquanto disciplina, através das notórias contribuições dos estudos estruturalistas de Ferdinand de Saussure. As ideias do autor alcançaram o mundo por intermédio da elaboração póstuma, "Curso de Linguística Geral", que foi produzida por um grupo de alunos da Universidade de Genebra, os quais foram discípulos de Saussure e tiveram acesso às suas notas - embora, conforme llari (2011), a complexidade dos pressupostos do linguista tenha sido minimizada no livro, fato constatado através das notas que realmente foram produzidas pelo autor, publicadas em um momento posterior.

Apesar das controvérsias existentes sobre a elaboração do "Curso de Linguística Geral", é válido destacar a importância de alguns conceitos apresentados em tal livro, aqui destacamos um: a Semiologia. Para o linguista, os seres humanos utilizam diversos signos para efetivarem a comunicação, tanto linguísticos, como de outras naturezas.

No entanto, para o linguista suíço, apenas os signos linguísticos estariam dentro do escopo da Linguística, enquanto todos os outros signos deveriam ser estudados por outra ciência, essa, por sua vez, seria mais abrangente do que a própria Linguística, a Semiologia. Diante dessa postulação, o cientista Charles Sanders Peirce demonstrou grande interesse nos estudos dos signos e aprofundou-se na Semiologia, que, posteriormente, foi denominada de Semiótica. 
Com o desenvolvimento das pesquisas nessa área, Peirce (apud SANTAELLA, 2007) conceituou os signos como unidades básicas de representação, em outros termos, são quaisquer coisas que sejam capazes de significar algo para alguém, pois o signo sinaliza um determinado objeto no mundo. Dessa forma, para a Semiótica de Peirce, assim como aponta Santaella (2007),

[...] o signo é uma coisa que representa uma outra coisa: seu objeto. Ele só pode funcionar como signo se carregar esse poder de representar, substituir uma outra coisa diferente dele. Ora, o signo não é o objeto. Ele apenas está no lugar do objeto. Portanto, ele só pode representar esse objeto de um certo modo e numa certa capacidade. (p.12)

Isto é, para o linguista americano, o signo estaria no plano da representação, não completa, de um objeto, assim, ele não toma o lugar do objeto, mas o representa, como por exemplo o signo "lápis", em que podemos perceber que ele não se torna o objeto por representá-lo.

Tanto Charles S. Peirce como Ferdinand de Saussure tinham base teórica e metodológica fincadas no Estruturalismo, por isso buscaram fragmentar o signo em dimensões, na tentativa de teorizar a complexidade dessas unidades de sentido. Em vista disso, Peirce (apud SANTAELLA, 2007) apresentou a relação triádica: o seu representamen (signo), o seu objeto e o seu interpretante (significado).

Além disso, o teórico também apresentou outras relações triádicas, tais como: ícone, índice e símbolo; e primeiridade (quali-signos), secundidade (sinsigno) e terceiridade (legi-signo). Através da primeira relação, o fundador da Semiótica classificou os signos em três tipos, em que o ícone é um signo que estabelece uma relação de semelhança qualitativa com o objeto a que se refere (similaridade); o índice é um signo que dá indício para realizar uma leitura (aproximação) e os símbolos são signos que convencionalmente passam a representar um determinado objeto (convenção).

A segunda relação, por sua vez, corresponde a três categorias que envolvem a leitura semiótica: Primeiridade, Secundidade e Terceiridade. Tais categorias são propostas por Charles S. Peirce da seguinte forma:

Parece, portanto, que as verdadeiras categorias são: primeira, sentimento, a consciência que pode ser compreendida como um instante do tempo, consciência passiva da qualidade, sem reconhecimento ou análise; segunda, consciência de uma interrupção no campo da consciência, 
sentido de resistência, de um fato externo ou outra coisa; terceira, consciência sintética, reunindo tempo, sentido, aprendizado, pensamento. [...] três concepções lógicas da qualidade, relação e mediação. A concepção da qualidade, que é absolutamente simples em si mesma e, no entanto, quando encarada em suas relações percebe-se que possui uma ampla variedade de elementos, surgiria toda vez que o sentimento ou a consciência singular se tornasse preponderante. A concepção de relação procede da consciência dupla ou sentido de ação e reação. A concepção de mediação origina-se da consciência plural ou sentido de aprendizado (PEIRCE, 2005, p. 14 apud MELO E MELO, 2013, p.25-26).

Isto é, a primeiridade está relacionada ao sentido primário que o signo pode ter, sem enfatizar a dimensão cultural (qualidades do signo). A secundidade diz respeito às somas das qualidades, que formam singularidades para a leitura dos signos. E, por fim, a terceiridade corresponde à propriedade de lei que faz o signo funcionar como uma convenção, tais signos são denominados legi-signos (tradução dos signos).

Para Santaella (2007), tal tríade é formada por camadas de interpretação, que ao tempo em que são simultâneas, consistem em processos distintos. Através de tais processos, conseguimos conhecer os níveis de interpretação e atribuição de sentido percorridos pela mente humana ao realizar a leitura de diferentes signos.

Dessa forma, é possível perceber que as categorias peirceanas, no que se refere à comunicação, propõem uma compreensão sobre o processo pelo qual os seres humanos reconhecem e interpretam os signos que compõem os atos de comunicação. Em um primeiro momento, os objetos do mundo real nos parecem qualidades, depois estabelecemos relações entre tal objeto e algo que já conhecemos. E, por fim, em um último grau de assimilação, a interpretação é concretizada (NICOLAU et al., 2010).

\section{Metodologia}

Neste artigo, buscamos analisar duas imagens que constituem releituras de pinturas renomadas: "Mona Lisa", de Leonardo da Vinci e "O Grito", de Edvard Munch. Tais releituras foram produzidas por alunos do oitavo ano do Colégio Marista, da cidade de São Paulo, em uma atividade proposta na disciplina de Artes, no período de quarentena, motivado pela pandemia mundial por covid-19, ocasionada pelo novo coronavírus. 
De acordo com a entrevista da professora Laís Bonfietti Figueiredo, veiculada no portal online de notícias "Estadão", em 2020, a atividade tinha por objetivo revisitar as pinturas renomadas, tendo em vista adaptá-las ao referido contexto social, proporcionando aos alunos uma reflexão sobre as relações existentes entre as produções artísticas e o contexto histórico pelos quais elas estão envolvidas. Cabe destacar que tais imagens foram escolhidas para tentarmos compreender de que forma estão ocorrendo expressões artísticas que representem o atual momento de crise na saúde pública.

Para realizar nossas análises, nos apoiamos nas categorias peirceanas de primeiridade, secundidade e terceiridade, buscando compreender os níveis de significação e sentido que podem ser alcançados através da leitura das imagens. Ressaltamos que para identificar cada imagem, utilizamos um código alfanumérico, composto pela letra "I", fazendo alusão ao objeto analisado (imagem), seguida da letra "A", em referência aos sujeitos que produziram tais imagens (os alunos) e, por fim, o número 1 e 2, indicando a ordem crescente dos números naturais.

Além disso, tomamos também como base algumas pesquisas que analisaram imagens a partir dessas três categorias, como em Dias e Gomes (2013), que analisaram uma fotografia do ensaio Fallen Princesses, Gomes e Dantas (2017), que analisaram anúncios publicitários, Moimaz e Molina (2009), tendo por objeto de análise pinturas históricas e tantas outras pesquisas que utilizaram as categorias de Charles S. Peirce.

\section{Análise de imagens}

A notícia veiculada no portal online "Estadão", que apresenta a atividade proposta pela professora Laís Bonfietti Figueiredo aos alunos do oitavo ano do Ensino Fundamental, do Colégio Marista de São Paulo, expõe ao público seis releituras de pinturas produzidas pelos alunos. No entanto, fizemos um recorte aleatório de tal amostra, escolhendo apenas duas imagens para realizarmos nossas análises. 


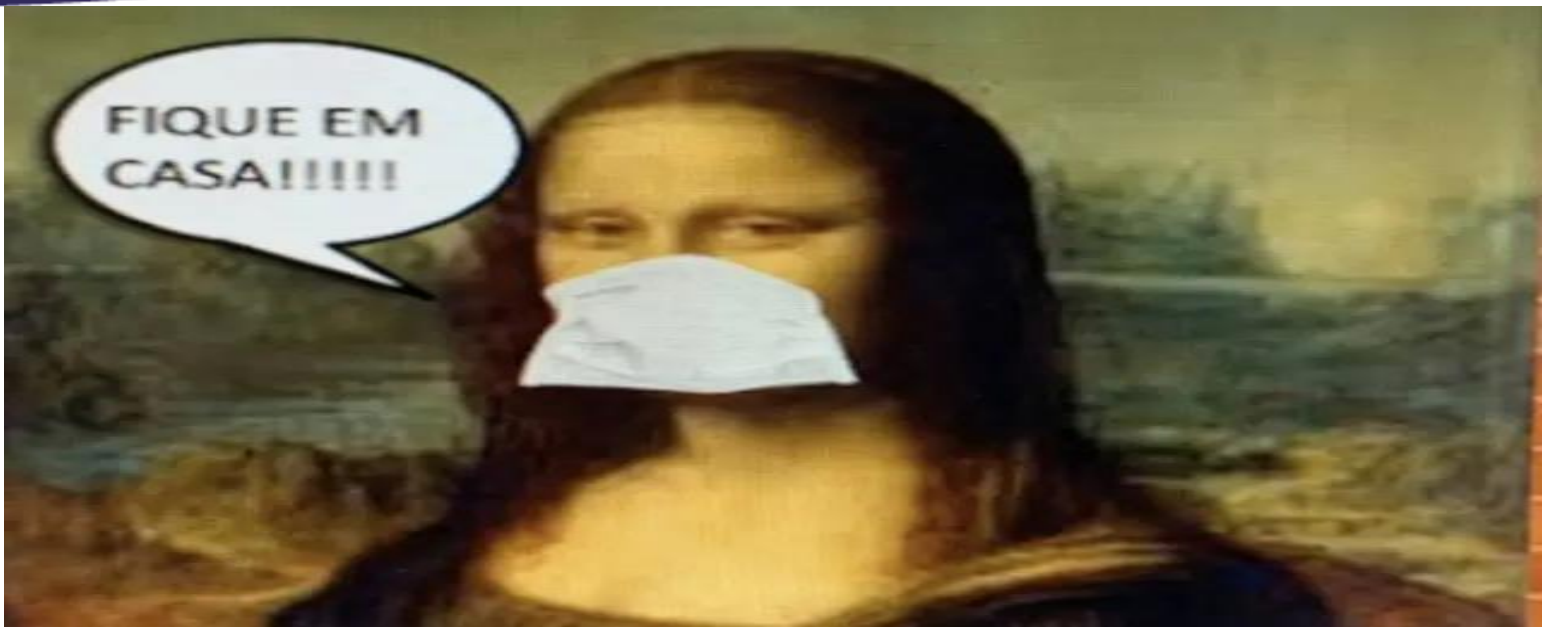

Figura 1: IA1.

A Fig. 1, IA1, acima, revisita a pintura "Mona Lisa", de Leonardo da Vinci, produzida no período Renascentista italiano. Tal pintura, é uma das mais notáveis produções de Da Vinci e também é conhecida como "La Gioconda".

Seguindo as categorias de análise da Semiótica peirciana, de acordo com Coelho Netto (1983), é na primeiridade que a mente humana consegue perceber o sentido mais superficial de uma imagem, ou seja, o indivíduo reconhece os elementos superficiais sobressalentes na imagem, sem qualquer reflexão prévia. Dessa forma, podemos perceber que, na primeiridade, o leitor reconhece os elementos visuais, como as cores escuras e claras que compõem a imagem, assim como a percepção de que os traços do pintor que formam uma mulher, apresentada com o rosto parcialmente coberto.

Além disso, os leitores de tal imagem, nessa categoria, são capazes de reconhecer os elementos verbais que nela estão presentes, nesse caso, o balão de fala posicionado próximo a cabeça da mulher retratada na imagem, contendo a frase "Fica em casa".

Na secundidade, por sua vez, a camada do significado é adentrada, é onde leitor reconhece o que há de concreto na imagem. Além de perceber os elementos que constituem tal texto imagético, tanto verbais como visuais, os leitores conseguem perceber que eles precisam de um referente para serem compreendidos.

$\mathrm{Na}$ Fig. 1, alcançando a secundidade, é possível que o interpretante reconheça que existem elementos, presentes na imagem, que estão sobrepostos, nesse caso, a máscara, que cobre parcialmente o rosto da figura feminina e o balão 
de fala com a frase "Fica em casa". Cada um desses elementos que constitui a Fig. 1 possui uma significação própria, entretanto, apesar de, nesse nível de interpretação, o leitor ser capaz de reconhecer a necessidade de um referente para que o sentido da imagem seja construído, a significação completa ainda não é atingida.

Por fim, é na terceiridade que o sentido completo é alcançado, é a categoria em que, a partir do reconhecimento dos elementos e dos significados que eles nos induzem a perceber, a reflexão acontece. Cada elemento deixa de ter um significado particular e passa a estabelecer relações uns com os outros, de maneira a constituir um significado mais amplo, atingindo o estágio real de significação.

Dessa forma, na Fig. 1, o leitor reconhece que a pintura de Leonardo da Vinci foi revisitada, portanto, o autor produziu uma releitura de tal pintura. "Mona Lisa", que antes era apresentada com o rosto descoberto, deixando à mostra um dos grandes detalhes dessa obra, que ao longo do tempo atraiu olhares de críticos e do público em geral, a quem, inclusive, atribui-se um mistério: o seu sorriso, agora tem seu rosto parcialmente coberto por uma máscara e recebe um balão de fala com a frase "Fique em casa".

Considerando o contexto de produção dessa imagem, o leitor consegue perceber que ela faz alusão à pandemia mundial por covid-19, ocasionada pelo novo coronavírus, que mudou o cotidiano das pessoas. As máscaras passaram a fazer parte do vestiário da população, tendo em vista a proteção individual contra o vírus. O elemento verbal, por sua vez, reforça a uma mensagem de conscientização que foi muito transmitida pelas autoridades de saúde, que orientaram a população a aderirem o isolamento social, com o objetivo de evitar a propagação do vírus. Assim, é possível dizer que além de revisitar a pintura e realizar uma releitura, o aluno deixa uma mensagem de conscientização para os leitores, estimulando-os a colaborarem com a orientação das autoridades de saúde. 


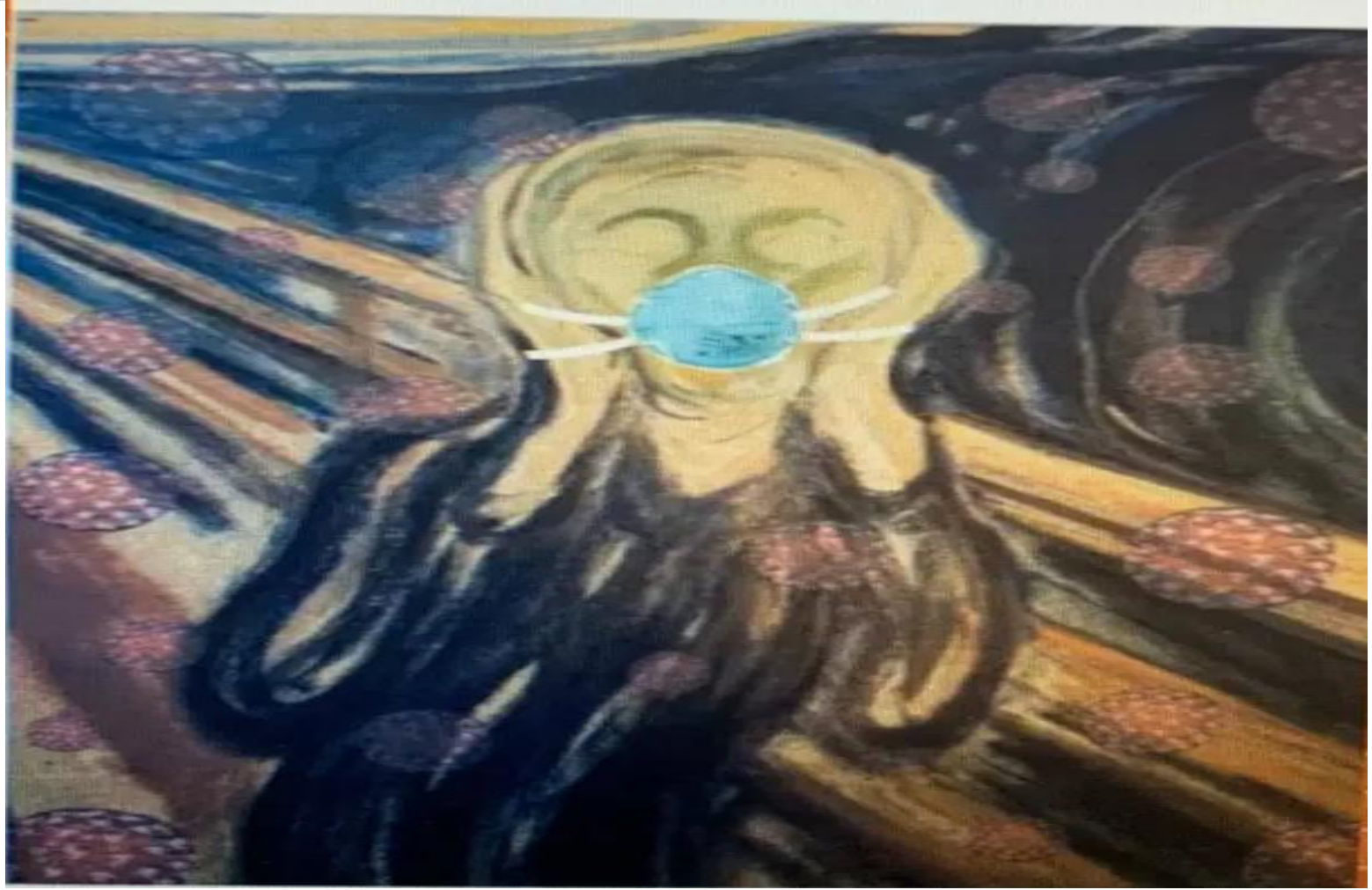

Figura 1: IA2.

Na Fig. 2, observamos que o aluno revisita a pintura "O Grito", de Edvard Munch. A pintura original teve grande destaque no cenário artístico como uma das principais obras que representam o movimento expressionista. Dentre as diversas interpretações atribuídas a esta pintura, as mais conhecidas são: a de que ela representaria um autorretrato dos sentimentos do artista que a pintou, uma vez que ele presenciou diversos horrores em sua vida pessoal e a de que ela expressava o contexto social em que a obra foi criada, no período entre as duas Grandes Guerras.

Analisando a imagem acima, partindo da categoria de Primeiridade, de Peirce, percebemos que os primeiros elementos que podem ser visualizados são as cores mais escuras, os traços que formam a sugestão de um ser humano, em que não é possível caracterizá-lo como um homem ou uma mulher, que está com as mãos no rosto e neste há uma máscara. Além disso, é possível observar, nesta primeira visão, que este ser atravessa uma ponte de madeira e neste ambiente é possível observar esferas (células) vermelhas por toda parte. Assim, na Primeiridade é possível perceber a imagem em si mesma, com suas características mais evidentes a um primeiro olhar. 
$\mathrm{Na}$ Secundidade, percebemos que é o momento que ocorre a interpretação do signo (nesse caso a pintura) para o que a imagem significa. Nesta imagem, podemos compreender, enquanto interpretantes, que ela significa um ser horrorizado e/ou assustado diante de alguma situação (que nesse caso entende-se como a crise de saúde pública decorrente da covid-19), uma vez que é comum, socialmente falando, que seja realizada a expressão física de pôr as mãos no rosto, ao lado da cabeça para demonstrar tais sentimentos e por se tratar de uma pintura expressionista, tal ação ficou ainda mais destacada.

Por fim, na Terceiridade, que seria uma "ponte" inteligível que liga a Primeiridade e a Secundidade, percebemos que é o momento em que o sentido total da imagem é formado, uma vez que são relacionados os elementos que primeiro são visualizados e a interpretação da imagem. Assim, compreendendo o sentido completo da imagem, podemos entender que os sentimentos de medo, horror e susto representados são formados com a união da imagem original (que já demonstrava esses sentimentos do pintor e do próprio contexto de guerra) e dos elementos adicionados pelo aluno na releitura, como a máscara e as células do vírus.

Assim, traçando um paralelo com a pintura original, em que os sentimentos interno e externo foram expressos na obra, podemos compreender a partir da análise dessa releitura que todo o ambiente ao redor desse ser está contaminado pelo vírus e isso compõe os sentimentos de medo e susto que são refletidos na expressão da imagem, isto é, o ambiente também constitui o indivíduo. Além disso, trazendo essa imagem para o social, podemos compreender que ela representa 0 sentimento de todas as pessoas que estão vivenciando o momento da pandemia, que se veem assustadas diante do vírus e utilizam como uma das principais formas de proteção o uso da máscara, o que novamente reforça a ideia de o meio formar o indivíduo.

\section{Considerações finais}

Percebendo os signos além do plano linguístico, Charles S. Peirce, ao elaborar sua teoria e propor as tricotomias, possibilitou a compreensão dos signos não-verbais ou visuais na realização da linguagem, uma vez que, como já é 
amplamente sabido, "a comunicação humana não se fundamenta apenas no código verbal [...]" (Gomes e Silva, 2020, p.9). Assim, a partir das proposições teóricas evidenciadas pelo autor é possível compreender de que forma a imagem é construída para se alcançar certa significação pelo interpretante.

Neste artigo, procuramos analisar duas releituras baseadas nas famosas obras "Mona Lisa", de Leonardo da Vinci, e "O Grito", de Edvard Munch, com base nas categorias Primeiridade, Secundidade e Terceiridade, de Charles S. Peirce.

A partir da análise dessas categorias compreendemos de que forma foi realizada a composição dos signos para que fossem realizados os processos de interpretação de seu significado, em que se parte de uma primeira apreensão de características mais visíveis em um olhar inicial (primeiridade), até a atribuição de sentidos que se dá a tais elementos após a interpretação (secundidade), sendo que esse processo é mediado pelo que podemos chamar metaforicamente de ponte (terceiridade) que liga a primeira concepção à segunda.

\section{Referências}

COELHO NETTO, J. T. Semiótica, informação e comunicação. São Paulo: Ed. Perspectiva. 1983.

DIAS, M. L. S; GOMES, F. W. B. Fallen Princesses: uma análise semiótica. Cadernos de Semiótica Aplicada (CASA), vol. 11.n.2, dezembro de 2013.

GOMES, F. W. B; SILVA. L. V. Letramento visual e a leitura de textos multimodais: um olhar sobre a relação entre imagem e texto visual na semiologia de Roland Barthes. In: LACERDA, N. A. (org.) Leitura, compreensão de textos e ensino: percepções, letramento visual e multimodalidade em diferentes gêneros e suportes. Teresina: EDUFPI. 2020.

GOMES, F. W. B; DANTAS, J. W. M. Uma análise de anúncios publicitários à luz das categorias fenomenológicas de Peirce. Revista Ininga, vol. 4, n.1, jan./jun. 2017.

ILARI, Rodolfo. O Estruturalismo Linguístico: alguns caminhos. In: BENTES, A. C; MUSSALIM, F. (org.). Introdução à Linguística: fundamentos epistemológicos. São Paulo: Cortez, 2011. p. 53-91.

MELO, Desirée Paschoal de; MELO, Venise Paschoal de. Uma introdução à semiótica peirceana. Paraná: UNICENTRO. 2013. 
MOIMAZ, Érica Ramos; MOLINA, Ana Heloísa. A contribuição da semiótica peirceana para análise da pintura histórica. Londrina: II Encontro Nacional de Estudos da Imagem. 2009.

NICOLAU, Marcos; ABATH, Daniel; LARANJEIRA, Pablo Cézar; MOSCOSO, Társila; MARINHO, Thiago; NICOLAU, Vitor. Comunicação e Semiótica: visão geral e introdutória à Semiótica de Peirce. Revista Eletrônica Temática, v.6, n.08. 2010.

SANTAELLA, Lucia. O que é semiótica. São Paulo: Brasiliense, 2007. 